\title{
PIGMENTAĈ̃O DE GEMAS DE OVOS DE CODORNAS JAPONESAS ALIMENTADAS COM RAÇÕES CONTENDO COLORÍFICO
}

\author{
Egg yolk colour of japanese quail fed on diets with spice
}

\author{
Newton Tavares Escocard de Oliveira ${ }^{1}$, José Brandão Fonseca², Rita da Trindade Ribeiro Nobre Soares², \\ Karla Silva Ferreira ${ }^{3}$, José Tarcísio Lima Thiébaut ${ }^{4}$
}

\begin{abstract}
RESUMO
Objetivou-se neste trabalho avaliar, semanalmente, o grau de pigmentação de gemas de ovos de codornas japonesas alimentadas com rações contendo diferentes níveis de colorífico (163,8 mg bixina/100 g), no decorrer de quatro semanas. Utilizaram-se 240 codornas japonesas (Coturnix japonica) fêmeas, em delineamento experimental em blocos inteiramente casualizados, com oito tratamentos, cinco repetições e seis codornas por unidade experimental. Os tratamentos, constituídos por oito rações experimentais resultantes da combinação de quatro níveis de colorífico na ração $(0 ; 1,5 ; 3,0$ e $4,5 \%)$ e duas fontes

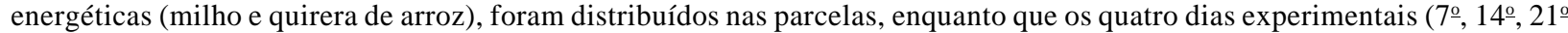
e 28ㅜ) constituíram as subparcelas. A equação de regressão estimada com o uso do modelo logarítmico explicou $96 \%$ da variação dos dados de escore colorimétrico das gemas. No 7ํ e 14을 dia do experimento, os níveis de colorífico estimados que promoveram escores colorimétricos de gemas com padrão caipira ( 8,5 a 9,0 pontos) foram de $1,5 \%$, em rações à base de milho, e $3,0 \%$, em rações à base de quirera de arroz. No $21^{\circ}$ e 28 o dia experimental, os valores estimados foram de $0,75 \%$ (rações com milho) e $2,25 \%$ (rações com quirera). Em rações com $46,0 \%$ de milho ou quirera de arroz, o uso de níveis superiores a 3,0\% de colorífico promoveu aumento das perdas de pigmento, pelas excretas, e conseqüiente redução da capacidade de deposição de pigmentos nas gemas.
\end{abstract}

Termos para indexação: Coturnix japonica, leque colorimétrico, pigmentos, quirera de arroz.

\section{ABSTRACT}

One aimed in this work to evaluate, weekly, the egg yolk colour grade of japanese quails fed on diets with different levels of spice ( $163.8 \mathrm{mg}$ bixin/100 g), in course of four weeks. Two hundred and forty japanese female quails (Coturnix japonica) were used in a completely randomized block outline, with eight treatments, five replicates and six quails per experimental unit. The treatments, consisted of eight experimental diets resultant from the combination of four spice levels in the diets $(0,1.5,3.0 \mathrm{e} 4.5 \%)$ and two energetic sources (corn and broken rice grains), were allotted to the plots, while the four experimental days $\left(7^{\text {th }}, 14^{\text {th }}, 21^{\text {st }}\right.$ e $\left.28^{\text {th }}\right)$ consisted the splitplots. The estimated regression equation with the use of logarithmic model explained $96 \%$ of the variation of yolk colour scores data. At the $7^{\text {th }}$ and $14^{\text {th }}$ experimental days, the estimated spice levels that promoted yolk colour scores with free-range pattern (8.5 to 9.0 points) were $1.5 \%$, for corn based rations, and $3.0 \%$, for broken rice grains based rations. At the $21^{\text {st }}$ and $28^{\text {th }}$ experimental day, the estimated values were $0.75 \%$ (diets with corn) and $2.25 \%$ (diets with broken rice grains). In diets with $46 \%$ of corn or broken rice grains, the use of upper levels to $3.0 \%$ of spice increased the pigment losses by excreta and consequent capacity decrease of store yolk pigments.

Index terms: Broken rice grains, colorimetric fan, Coturnix japonica, pigments.

(Recebido em 21 de dezembro de 2006 e aprovado em 9 de maio de 2007)

\section{INTRODUÇÃO}

Entre os atributos sensoriais, a cor tem sido relacionada como indicador de qualidade, exercendo papel importante na aceitação dos alimentos pelos consumidores (PEREIRA et al., 2001; SILVA et al., 2000; TOCCHINI \& MERCADANTE, 2001).

Em escala comercial e de forma idêntica à produção de ovos de galinhas poedeiras, os ovos de codornas são produzidos por meio do fornecimento ininterrupto de rações para postura à base de milho amarelo e farelo de soja, o que tem garantido uma pigmentação de gema que pode variar do amarelo ao laranja. A intensidade de cor das gemas, decorrente da incorporação de xantofilas, principalmente luteína e zeaxantina presentes no milho, é dependente dos níveis de inclusão do milho amarelo nas rações de codornas poedeiras.

'Doutor em Produção Animal - Laboratório de Engenharia Agrícola/LEAG - Universidade Estadual do Norte Fluminense Darcy Ribeiro/UENF - Avenida Alberto Lamego, 2000, Parque Califórnia - 28013-602 - Campos dos Goytacazes, RJ - newtonescocard@hotmail.com

2Doutores, Professores - Laboratório de Zootecnia e Nutrição Animal/LZNA - Universidade Estadual do Norte Fluminense Darcy Ribeiro/UENF _ Avenida Alberto Lamego, 2000, Parque Califórnia - 28013-602 - Campos dos Goytacazes, RJ - jfonseca@uenf.br; rnobre@uenf.br ${ }^{3}$ Doutora em Ciência e Tecnologia de Alimentos, Professora - Laboratório de Tecnologia de Alimentos/LTA - Universidade Estadual do Norte Fluminense Darcy Ribeiro/UENF - Avenida Alberto Lamego, 2000, Parque Califórnia - 28013-602 - Campos dos Goytacazes, RJ - karlasf@uenf.br ${ }^{4}$ Doutor em Produção Animal, Professor - Laboratório de Engenharia Agrícola/LEAG - Universidade Estadual do Norte Fluminense Darcy Ribeiro/UENF Avenida Alberto Lamego, 2000, Parque Califórnia - 28013-602 - Campos dos Goytacazes, RJ - jtt1512@uenf.br 
Em ovos de codornas, tem sido comum a ocorrência de gemas "in natura" produzidas com pigmentação deficiente, com redução na coloração das gemas de ovos cozidos, a forma mais freqüente de consumo. Ovos de codornas cozidos com gemas pouco pigmentadas são menos atrativos para o consumidor e uma solução possível é a inclusão de corantes lipossolúveis às rações, que aumenta a deposição de carotenóides e a coloração das gemas (PEREIRA et al., 2001; SILVA et al., 2000).

A maior exigência dos consumidores por produtos saudáveis e as proibições legais de uso de corantes sintéticos às rações animais e aos alimentos de consumo humano têm promovido crescente aceitação na incorporação de corantes naturais a tais alimentos. $\mathrm{O}$ uso do urucum (Bixa orellana L.) representa cerca de $90 \%$ dos corantes naturais usados no Brasil e 70\% no mundo. Do total de sementes de urucum produzidas no Brasil, cerca de $75 \%$ são usadas na fabricação de coloríficos, consumidos integralmente no mercado interno e de uso quase exclusivamente doméstico (TOCCHINI \& MERCADANTE, 2001).

O uso de coloríficos em rações de poedeiras pode constituir-se em alternativa viável para se obter gemas de ovos de codornas mais pigmentadas, tendo em vista a elevada proporção do carotenóide lipossolúvel bixina e a facilidade de obtenção do produto no mercado. Entretanto, Tocchini \& Mercadante (2001) verificaram uma grande variação nos teores de bixina (154 a $354 \mathrm{mg}$ ) encontrada em amostras de $100 \mathrm{~g}$ de colorífico, constituindo-se em fator negativo quanto a sua inclusão na alimentação de poedeiras.

Pereira et al. (2000), avaliando níveis de 0,05, 0,10, 0,15 e $0,2 \%$ de extrato oleoso de urucum (EU) na ração, verificaram aumento linear da coloração das gemas dos ovos de galinhas poedeiras, produzidos durante dois ciclos de 28 dias. Cores de gemas similares foram obtidas com o uso de ração com $63 \%$ de sorgo, fonte energética isenta de pigmentos, adicionada de $0,2 \%$ de EU, quando comparada com ração contendo $61 \%$ de milho e sem EU.

A inclusão de $0,45 \%$ de EU à ração contendo farelo de soja $(21,45 \%)$, milho $(25,45 \%)$ e sorgo $(41,4 \%)$ produziu uma coloração de gema de ovos de poedeiras leves igual a 8,87 pontos no leque colorimétrico (DSM), valor encontrado na faixa referencial ( 8,5 a 9,0 pontos) para aves caipiras (SILVA et al., 2000).

Segundo Pereira et al. (2001), houve intensificação linear $(\mathrm{P} \leq 0,05)$ da cor das gemas de ovos de poedeiras com o aumento dos níveis de $\mathrm{EU}(0 ; 0,05 ; 0,10 ; 0,15$ e $0,20 \%)$, em rações à base de milho, em dois ciclos de produção de 28 dias (aves com 44 a 52 semanas). Os escores colorimétricos médios foram 7,13; 7,26; 7,81; 8,61 e 9,14, respectivamente, nos níveis de 0 a $0,20 \%$ de adição de EU, medidos nos dois últimos dias de cada ciclo, logo após a coleta.

Melo et al. (2003) ajustaram o modelo quadrático $\left(\hat{\mathrm{Y}}=3,73+13,92 \mathrm{X}-26,99 \mathrm{X}^{2} ; \mathrm{R}^{2}=0,94\right)$ e o linear response plateau (LRP) $\left(\hat{Y}=3,60+10,50 X ; R^{2}=0,85\right)$ para a coloração de gemas, avaliadas em cinco períodos de 22 dias, em função de níveis de EU $(0 ; 0,1 ; 0,2$ e $0,4 \%)$ na ração de codornas européias, com $50 \%$ de substituição do milho pelo sorgo. O nível ótimo estimado de adição do EU foi de $0,26 \%$, pelo modelo quadrático, e de $0,20 \%$ pelo LRP.

Pereira et al. (2001) realçaram o efeito do uso de EU em rações sobre a cor de gemas no decorrer do tempo. A pigmentação estimada das gemas de ovos de galinhas que receberam rações à base de milho e suplementadas com EU entre 48 e 52 semanas ( $\hat{Y}=7,34+11,20 X ; R^{2}=0,52$ ) foi mais intensa do que a cor das gemas avaliadas durante a $44^{\circ}$ e $48^{\circ}$ semana $\left(\hat{Y}=6,49+10 X ; R^{2}=0,47\right)$.

Objetivou-se neste trabalho avaliar, semanalmente, o efeito do colorífico na pigmentação das gemas dos ovos de codornas japonesas, durante quatro semanas.

\section{MATERIAL E MÉTODOS}

O experimento foi realizado em agosto de 2002, no Campo Experimental da Universidade Estadual do Norte Fluminense Darcy Ribeiro (Uenf), localizada no Município de Campos dos Goytacazes.

Foram utilizadas 240 codornas japonesas (Coturnix japonica) fêmeas, em delineamento experimental de blocos inteiramente casualizados, com oito tratamentos, cinco repetições e seis codornas por unidade experimental (gaiola de $1,00 \mathrm{~m}$ de comprimento $\mathrm{x} 0,34 \mathrm{~m}$ de largura $\mathrm{x} 0,24 \mathrm{~m}$ de altura).

Os tratamentos, constituídos por oito rações experimentais oriundas da combinação de quatro níveis de colorífico, produto constituído pela mistura de fubá ou farinha de mandioca com urucum em pó ou extrato oleoso de urucum (EU), adicionados ou não de sal e de óleos comestíveis (TOCCHINI \& MERCADANTE, 2001), na ração $(0 ; 1,5 ; 3,0$ e 4,5\%) x duas fontes energéticas (milho e quirera de arroz), foram casualizados em cada bloco e distribuídos nas parcelas, enquanto que os quatro dias experimentais $\left(7^{\circ}, 14^{\circ}, 21^{\circ}\right.$ e $\left.28^{\circ}\right)$ constituíram as subparcelas (esquema de parcelas subdivididas).

Cada bloco foi composto por duas gaiolas, que correspondeu a um nível de altura de gaiolas inseridas em baterias de madeira, e teve a finalidade de eliminar uma possível influência da luminosidade nos cinco diferentes andares de gaiolas. 
As codornas com idade inicial de 80 dias foram alojadas em galpão de alvenaria, contendo duas baterias de madeira que agruparam dez gaiolas metálicas de quatro divisões internas cada. Em cada gaiola foram abrigadas 24 codornas. As aves receberam água e ração à vontade, em bebedouros e comedouros de chapa galvanizada.

Durante o período experimental, a amplitude de temperatura no interior do galpão, registrada com auxílio de um termômetro de máxima e mínima, variou de 19,5 a $33^{\circ} \mathrm{C}$.

Antes do início do experimento, por um período de 43 dias, as codornas receberam ração pré-experimental formulada com níveis mínimos de pigmentos, visando a esgotar o estoque de pigmentos em seus organismos. A partir do $80^{\circ}$ dia de idade as codornas receberam as rações experimentais, sendo isoprotéicas e isoenergéticas. As composições percentuais da ração pré-experimental e das rações experimentais, e seus valores nutricionais calculados encontram-se na Tabela 1.

Nas formulações das rações experimentais, foram utilizados os valores de energia metabolizável aparente corrigida pelo balanço de nitrogênio (EMAn), em quilocaloria por quilograma de matéria natural do milho (3.122), farelo de soja (2.651), quirera de arroz (2.947), colorífico (3.102) e óleo de soja degomado (7.940), determinados previamente em ensaio de digestibilidade, utilizando-se codornas japonesas fêmeas com idade entre 31 e 36 dias (OLIVEIRA et al., 2007). O valor energético usado para o óleo de soja refinado foi o obtido com o teste do óleo de soja degomado.

No cálculo das rações experimentais, foram utilizados os valores de proteína bruta, cálcio e fósforo total do milho, farelo de soja, quirera de arroz e colorífico, determinados previamente, segundo Silva \& Queiroz (2002) (Tabela 2).

TABELA 1 - Composições percentuais e valores nutricionais calculados da ração pré-experimental (RPE) e das rações experimentais $(\mathrm{RE})$, na matéria natural.

\begin{tabular}{|c|c|c|c|c|c|c|c|c|c|}
\hline \multirow{2}{*}{$\begin{array}{l}\text { Ingredientes (\%) } \\
\text { Milho }\end{array}$} & \multirow{2}{*}{$\frac{\text { RPE }}{-}$} & \multicolumn{4}{|c|}{ RE com milho } & \multicolumn{4}{|c|}{ RE com quirera } \\
\hline & & 46,00 & 46,00 & 46,00 & 46,00 & - & - & - & - \\
\hline Quirera de arroz & 46,00 & - & - & - & - & 46,00 & 46,00 & 46,00 & 46,00 \\
\hline Farelo de soja & 36,83 & 36,73 & 36,52 & 36,29 & 36,06 & 36,83 & 36,61 & 36,40 & 36,17 \\
\hline Óleo de soja refinado & 6,99 & 6,07 & 5,60 & 5,14 & 4,68 & 6,99 & 6,52 & 6,06 & 5,60 \\
\hline Calcário & 5,34 & 5,40 & 5,40 & 5,40 & 5,40 & 5,34 & 5,34 & 5,34 & 5,34 \\
\hline Colorífico & - & 0 & 1,50 & 3,00 & 4,50 & 0 & 1,50 & 3,00 & 4,50 \\
\hline Fosfato bicálcico & 1,23 & 1,21 & 1,20 & 1,20 & 1,20 & 1,23 & 1,23 & 1,23 & 1,23 \\
\hline $\begin{array}{l}\text { Suplemento mineral } \\
\text { vitamínico }^{1}\end{array}$ & 0,40 & 0,40 & 0,40 & 0,40 & 0,40 & 0,40 & 0,40 & 0,40 & 0,40 \\
\hline Cloreto de sódio & 0,27 & 0,28 & 0,28 & 0,28 & 0,28 & 0,27 & 0,27 & 0,26 & 0,26 \\
\hline DL-Metionina & 0,11 & 0,12 & 0,12 & 0,12 & 0,12 & 0,11 & 0,11 & 0,11 & 0,11 \\
\hline Inerte & 2,83 & 3,79 & 2,98 & 2,17 & 1,36 & 2,83 & 2,02 & 1,20 & 0,39 \\
\hline \multicolumn{10}{|c|}{ Composição química (\%) } \\
\hline EM (kcal/kg) & 2.900 & 2.900 & 2.900 & 2.900 & 2.900 & 2.900 & 2.900 & 2.900 & 2.900 \\
\hline Proteína bruta & 21,00 & 21,00 & 21,00 & 21,00 & 21,00 & 21,00 & 21,00 & 21,00 & 21,00 \\
\hline Metionina + cistina & 0,83 & 0,86 & 0,86 & 0,86 & 0,86 & 0,83 & 0,83 & 0,83 & 0,83 \\
\hline Metionina & 0,54 & 0,54 & 0,54 & 0,54 & 0,54 & 0,54 & 0,54 & 0,54 & 0,54 \\
\hline Lisina & 1,15 & 1,14 & 1,13 & 1,13 & 1,13 & 1,15 & 1,15 & 1,15 & 1,15 \\
\hline Treonina & 0,78 & 0,80 & 0,81 & 0,81 & 0,81 & 0,78 & 0,78 & 0,79 & 0,79 \\
\hline Cálcio & 2,50 & 2,50 & 2,50 & 2,50 & 2,50 & 2,50 & 2,50 & 2,50 & 2,50 \\
\hline Fósforo disponível & 0,35 & 0,35 & 0,35 & 0,35 & 0,35 & 0,35 & 0,35 & 0,35 & 0,35 \\
\hline Sódio & 0,15 & 0,15 & 0,15 & 0,15 & 0,15 & 0,15 & 0,15 & 0,15 & 0,15 \\
\hline Extrato etéreo & 7,88 & 8,17 & 7,75 & 7,34 & 6,92 & 7,88 & 7,46 & 7,05 & 6,63 \\
\hline
\end{tabular}

${ }^{(1)}$ Quantidades em 1000 g: vit. A - 2.500.000 UI; vit. $D_{3}-625.000 \mathrm{UI}$; vit. E - $3.750 \mathrm{UI}$; vit. $\mathrm{K}_{3}$ - 500 mg; vit. $\mathrm{B}_{1}$ - $500 \mathrm{mg}$; vit. $\mathrm{B}_{2}-1.000 \mathrm{mg}$; vit. $\mathrm{B}_{6}-1.000 \mathrm{mg}$; vit. $\mathrm{B}_{12}-3.750 \mathrm{mcg}$; niacina - $7.500 \mathrm{mg}$; ác. Pantotênico - $4.000 \mathrm{mg}$; biotina - 15 mg; ác. Fólico - 125 mg; colina - 75.000 mg; metionina - 250.000 mg; Se - 45 mg; I - 175 mg; Fe - 12.525 mg; Cu - 2.500 mg; Mn - 19.500 mg; Zn - 13.750 mg; avilamicina - 20.000 mg; BHT - 500 mg; vit. C - 12.500 mg. 
TABELA 2 - Composição bromatológica (\%) de alguns ingredientes utilizados nas rações experimentais, expressa na base da matéria natural.

\begin{tabular}{lcccc}
\hline Ingredientes & Matéria Seca & Proteína Bruta & Cálcio & Fósforo Total \\
\hline Milho & 86,77 & 7,99 & 0,04 & 0,32 \\
Farelo de soja & 87,77 & 46,81 & 0,29 & 0,63 \\
Quirera de arroz & 86,27 & 7,89 & 0,07 & 0,29 \\
Colorífico & 88,30 & 7,00 & 0,05 & 0,15 \\
\hline
\end{tabular}

A quantificação do teor de bixina do colorífico foi feita por dosagem do norbixinato de potássio, obtido a partir da extração e saponificação da bixina e norbixina do colorífico com KOH a 0,5\% (YABIKU \& TAKAHASHI, 1992). Utilizou-se o coeficiente de extinção de 3473, em cela de $1 \mathrm{~cm}$ de percurso ótico. A leitura espectrofotométrica foi feita em $1_{\text {máx. }}=453 \mathrm{~nm}$ (TOCCHINI \& MERCADANTE, 2001). A concentração obtida do sal de potássio de norbixina foi convertida em bixina por divisão pelo fator 1,16. O valor médio (triplicata) obtido foi de $163,8 \mathrm{mg}$ de bixina por $100 \mathrm{~g}$ de colorífico.

Exceto os nutrientes cujos valores foram mencionados, todas as rações foram formuladas de acordo com as composições químicas dos demais ingredientes apresentados por Rostagno et al. (2000) e adequadas às exigências nutricionais para codornas japonesas do NRC (NRC, 1994), à exceção dos níveis de proteína bruta, metionina + cistina, metionina, lisina e treonina.

Foi avaliada a cor das gemas no 7ㅇ; $14^{\circ} ; 2^{\circ}$ o e $28^{\circ}$ dia do experimento. Oitenta ovos (dez por tratamento e dois por repetição) foram coletados aleatoriamente, identificados e acondicionados em embalagens para ovos de codorna. Após cada coleta, um ovo por vez foi aberto por meio de quebra da casca na região da câmara de ar, sua gema foi separada do albume (manualmente), sendo colocada em recipiente plástico, de cor branca e de pequena profundidade, limpo e seco após cada classificação. A cor de cada gema "in natura" foi visualmente comparada e classificada utilizando-se o leque colorimétrico (DSM), com escore de um a quinze, sob luz natural. A análise de cor realizou-se na parte da manhã, logo após cada coleta, em sala próxima ao galpão experimental e feita por um único avaliador.

Os efeitos de nível de colorífico, dia experimental e fonte energética sobre a cor das gemas foram verificados pela análise de variância e estimados por meio de equações de regressão linear múltipla a $5 \%$ de probabilidade, utilizando-se variáveis dummy (valores binários) para as variáveis independentes, dia experimental e fonte energética. Todas as análises estatísticas foram feitas usando-se o Sistema de Análises Estatísticas e Genéticas (SAEG) (UFV, 2003).

\section{RESULTADOS E DISCUSSÃO}

A equação de regressão geral estimada do logaritmo (base dez) do escore colorimétrico (LÊC) em função de logaritmo (base dez) do nível de colorífico (LNC), dia experimental (D) e fonte energética (FE) foi $=0,93+0,14$ $\mathrm{LNC}-0,14 \mathrm{DFE}+0,07 \mathrm{DD}_{1}+0,02 \mathrm{DD}_{2}+0,20$ DFE.LNC $0,05 \mathrm{DD}_{1} . \mathrm{LNC}\left(\mathrm{R}^{2}=0,96\right)$.

O coeficiente de determinação obtido mostrou que a equação de regressão estimada explicou $96 \%$ da variação dos dados de escore colorimétrico, sugerindo elevada confiabilidade nas estimativas com o ajuste do modelo logarítmico aos dados.

Considerando-se as combinações milho $\mathrm{x}$ dia experimental 7 e milho $\mathrm{x}$ dia 14, a equação de regressão estimada foi $=0,93+0,14 \mathrm{LNC}$ ou $=8,5114 \cdot \mathrm{NC}^{0,14}$. Para a combinação milho $\mathrm{x}$ dia 21 e milho $\mathrm{x}$ dia 28 , as equações estimadas foram $=0,95+0,14 \mathrm{LNC}$ ou $=8,9125 \cdot \mathrm{NC}^{0,14} \mathrm{e}=1,00$ $+0,09 \mathrm{LNC}$ ou $=10,00 \cdot \mathrm{NC}^{0,09}$, respectivamente (Figura 1).

Considerando-se as combinações quirera de arroz $\mathrm{x}$ dia experimental 7 e quirera de arroz x dia 14, a equação de regressão estimada foi $=0,79+0,34 \mathrm{LNC}$ ou $=6,1659 \cdot \mathrm{NC}^{0,34}$. A equação estimada para a combinação quirera de arroz x dia 21 foi $=0,81+0,34 \mathrm{LNC}$ ou $=6,4565 \cdot \mathrm{NC}^{0,34}$ e para quirera de arroz $\mathrm{x}$ dia 28 foi $=0,86+0,29 \mathrm{LNC}$ ou $=7,2444 . \mathrm{NC}^{0,29}$ (Figura 2).

Estes resultados mostraram que a estimativa do escore colorimétrico das gemas ( $\hat{\mathrm{E} C}$ ) se aproximou de um valor máximo à medida que foram aumentados os níveis de pigmento nas rações. Esse comportamento não foi obtido por Pereira et al. $(2000,2001)$, que encontraram efeito linear de $1^{\circ}$ grau de níveis crescentes de extrato oleoso de urucum (EU), em rações à base de milho, sobre a coloração de gema medida em dois ciclos de produção de 28 dias. Resultados também contraditórios foram apontados por Melo et al. (2003), que ajustaram os modelos quadrático e linear response plateau para estimar o nível ótimo de EU sobre a coloração de gemas em codornas européias alimentadas com ração com $50 \%$ de substituição do milho pelo sorgo. 


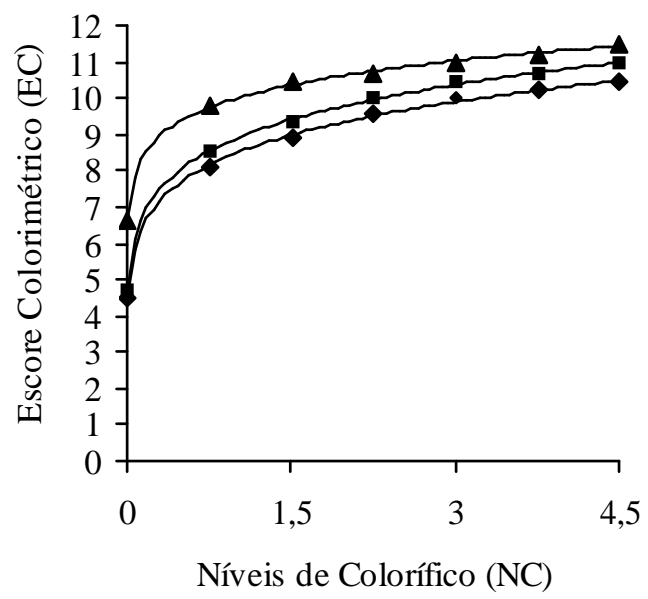

$\triangle \mathrm{EC}=10,00 . \mathrm{NC}^{\wedge} 0,09$ (milho $\mathrm{x}$ dia 28 )

- $\mathrm{EC}=8,9125 \cdot \mathrm{NC}^{\wedge} 0,14$ (milho $\mathrm{x}$ dia 21 )

- $\mathrm{EC}=8,5114 \cdot \mathrm{NC}^{\wedge} 0,14$ (milho $\mathrm{x}$ dia 7 e milho $\mathrm{x}$ dia 14 )

FIGURA 1 - Estimativas do escore colorimétrico (EC) em função dos níveis de colorífico (NC), em cada combinação de milho $\mathrm{x}$ dia experimental.

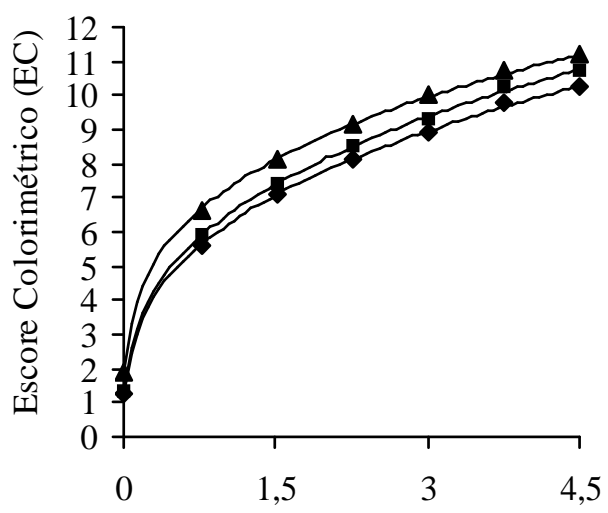

Níveis de Colorífico (NC)

$\Delta \mathrm{EC}=7,2444 . \mathrm{NC}^{\wedge} 0,29$ (quirera de arroz $\mathrm{x}$ dia 28 )

- $\mathrm{EC}=6,4565 \cdot \mathrm{NC}^{\wedge} 0,34$ (quirera de arroz $\mathrm{x}$ dia 21 )

- $\mathrm{EC}=6,1659 . \mathrm{NC}^{\wedge} 0,34$ (quirera $\mathrm{x}$ dia 7 e quirera $\mathrm{x}$ dia 14 )

FIGURA 2 - Estimativas do escore colorimétrico (EC) em função dos níveis de colorífico (NC), em cada combinação de quirera de arroz x dia experimental. 
Observou-se que a pigmentação das gemas no $28^{\circ}$ dia foi maior do que no $21^{\circ}$ dia e no $7^{\circ}$ ou $14^{\circ}$ dia, independentemente da fonte energética ou de nível de colorífico utilizado (Figuras 1 e 2). Esses resultados mostram que a deposição de pigmentos é maior no decorrer do tempo, sendo coincidentes com os apresentados por Pereira et al. (2001), que verificaram que a pigmentação estimada das gemas de ovos de galinhas alimentadas com rações à base de milho e suplementadas com EU, no período de 48 e 52 semanas $(\hat{Y}=7,34+11,20 X)$ foi mais intensa do que a cor das gemas avaliadas entre a $44^{\circ}$ e $48^{\circ}$ semana $(=6,49+10 \mathrm{X})$.

A cor estimada no $21^{\circ}$ dia foi mais intensa do que no 7o ou $14^{\circ}$ dia, em todas as fontes energéticas e níveis de colorífico (Figuras 1 e 2). A não inclusão $(0,01 \%)$ do colorífico nas rações promoveu estimativas de cor das gemas de 4,47 (dia 7 ou 14) e 4,68 (dia 21) para codornas alimentadas com milho, e de 1,29 (dia 7 ou 14) e 1,35 (dia 21) para codornas que receberam quirera de arroz. Esses resultados mostram que a não inclusão do colorífico causa menor magnitude de aumento na pigmentação de gemas do $14^{\circ}$ dia para o $21^{\circ}$ dia do que com o uso de 1,5; 3,0 e 4,5\% de colorífico (Figuras 1 e 2), sugerindo uma maior deposição de pigmentos nas gemas a partir do $14^{\circ}$ dia com a suplementação do colorífico nas rações.

As equações da Figura 1 não mostraram diferença significativa $(\mathrm{P}>0,05)$ entre os interceptos e declividades das curvas obtidas nos dias 7 e 14. Os interceptos das curvas obtidas nos dias 7 ou 14, 21 e 28 foram significativamente diferentes $(\mathrm{P} \leq 0,05)$. As declividades das curvas obtidas no $7^{\circ}$, $14^{\circ}$ e $21^{\circ}$ dia foram equivalentes $(\mathrm{P}>0,05)$, mas diferentes $(\mathrm{P} \leq 0,05)$ da declividade da equação estimada no $28^{\circ}$ dia.

As estimativas pontuais de escore colorimétrico em função do nível de $1,5 \%$ de colorífico obtidas nas combinações milho x dia 7 e milho $\mathrm{x}$ dia 14 , foram de 9,00 pontos no leque colorimétrico da DSM (Figura 1). Essa estimativa encontrou-se na faixa referência $(8,5$ a 9,0 pontos) para ovos do tipo caipira (SILVA et al., 2000) e foi $1,5 \%$ inferior ao valor médio observado de $\mathrm{EC}(9,14)$ obtido por poedeiras alimentadas com ração à base de milho adicionada de 0,20\% de EU (PEREIRA et al., 2001). Esta semelhança entre valores de EC pode estar associada ao teor de bixina do EU e do colorífico e à proporção de uso nas rações.

Considerando-se os dados de utilização do milho no 21 o e no 28 o dia após o uso do pigmento, as estimativas do escore colorimétrico em função do nível de $0,75 \%$ de colorífico foram de 8,56 e 9,74 pontos, respectivamente (Figura 1). Essas estimativas atendem ao padrão colorimétrico de classificação para gemas de ovos do tipo caipira, cuja pontuação está na faixa referencial de 8,5 a 9,0 pontos (SILVA et al., 2000), o que sugere uma possível valorização e maior aceitação dos ovos pelos consumidores.

As equações da Figura 2 não mostraram diferença significativa $(\mathrm{P}>0,05)$ entre os coeficientes lineares $\mathrm{e}$ angulares das curvas obtidas nos dias 7 e 14. Os coeficientes lineares das curvas obtidas nos dias 7 ou 14 , 21 e 28 foram significativamente diferentes $(\mathrm{P} \leq 0,05)$. Os coeficientes angulares das curvas obtidas no 7o, $14^{\circ}$ e $21^{\circ}$ dia foram equivalentes $(\mathrm{P}>0,05)$, mas diferentes $(\mathrm{Pd}$ '0,05) do coeficiente angular da equação estimada no dia 28.

As estimativas pontuais de escore colorimétrico em função do nível de 3,0\% de colorífico obtidas nas combinações quirera de arroz x dia 7 e quirera x dia 14 , foram de 8,96 pontos no leque colorimétrico da DSM (Figura 2). Esse valor encontra-se na faixa referencial (8,5 a 9,0 pontos) para ovos do tipo caipira (SILVA et al., 2000) e foi $0,44 \%$ menor do que o valor médio estimado de EC (= $9,00)$ em função do nível de $1,5 \%$ de colorífico obtido nas combinações milho x dia 7 e milho x dia 14 (Figura 1). Esses resultados mostraram que para as duas primeiras semanas de uso de pigmento nas rações, a pigmentação estimada da gema obtida pela ração à base de milho $+1,5 \%$ de colorífico foi similar à obtida pela ração à base de quirera de arroz $+3,0 \%$ de colorífico. Isso pode ser atribuído a fatores como quantidade de pigmentos presentes no milho e na quirera, a eficiência de absorção e de deposição na gema dos diferentes carotenóides (bixina, luteína, zeaxantina), entre outros.

Para a obtenção de estimativa de escore colorimétrico de ovos classificados como caipiras $(8,5$ a 9,0 pontos) (SILVA et al., 2000), pode-se observar que ovos de codornas alimentadas com rações com quirera de arroz proporcionaram estimativas de escore colorimétrico em função do nível de 2,25\% de colorífico de 8,51 no 21ํ dia e 9,16 no $28^{\circ}$ dia após o uso do pigmento (Figura 2). Essas estimativas apontam para uma redução do uso de níveis de colorífico (de 3,0\% para 2,25\%) após a segunda semana de uso de pigmento nas rações à base de quirera de arroz.

Baseado nos valores estimados de cor de gemas obtidos nas Figuras 1 e 2 podem-se observar que independentemente dos dias experimentais, o uso de níveis superiores a 3,0\% de colorífico em rações à base de 46,0\% de milho ou quirera de arroz, promoveu redução na eficiência de deposição de bixina nas gemas. Essa baixa eficiência pôde ser visualmente observada e comprovada no decorrer do experimento, visto que as excretas das codornas que receberam rações com $3,0 \%$ e $4,5 \%$ de 
colorífico apresentaram-se com intensa coloração vermelha, o que significou elevada perda de pigmentos ou baixa taxa de absorção de bixina.

\section{CONCLUSÕES}

O uso de colorífico com $163,8 \mathrm{mg}$ de bixina por 100 $\mathrm{g}$ intensifica a coloração de gemas de ovos de codornas japonesas.

A cor das gemas de ovos de codornas japonesas se intensifica quando se utiliza, ininterruptamente, coloríficos na ração por um tempo mínimo de 21 dias.

O uso de 1,5\% de colorífico em rações à base de $46,0 \%$ de milho e de 3,0\% de colorífico em rações à base de $46,0 \%$ de quirera de arroz, promove pigmentação de gemas do tipo caipira, no período entre o início do uso do colorífico até o $14^{\circ}$ dia.

O uso de $0,75 \%$ de colorífico em rações à base de $46,0 \%$ de milho e de 2,25\% de colorífico em rações à base de $46,0 \%$ de quirera de arroz, promove pigmentação de gemas do tipo caipira, no período entre o $14^{\circ}$ e o $28^{\circ}$ dia após o uso do colorífico na ração.

\section{REFERÊNCIAS BIBLIOGRÁFICAS}

MELO, D. A.; SILVA, J. H. V.; ANDRADE, I. S.; SILVA, E. L.; JANUÁRIO FILHO, J.; RIBEIRO, M. L. G.; SANTOS, J. L.; ROCHA, M. R. F.; COSTA, F. G. P.; CARNEIRO, M. V. D. Níveis de substituição do milho pelo sorgo e uso do extrato oleoso de bixina como corante da gema dos ovos de codornas. In: REUNIÃO ANUAL DA SOCIEDADE BRASILEIRA DE ZOOTECNIA, 40., 2003, Santa Maria, RS. Anais... Santa Maria: SBZ, 2003. CD-ROM.

NATIONAL RESEARCH COUNCIL. Nutrient requirements of poultry. 9. ed. Washington, DC: National Academy, 1994. $155 \mathrm{p}$.

OLIVEIRA, N. T. E.; FONSECA, J. B.; SOARES, R. T. R. N.; LOMBARDI, C. T.; MERCADANTE, M. B. Determinação da energia metabolizável de diferentes alimentos testados em codornas japonesas fêmeas. Arquivo Brasileiro de Medicina Veterinária e Zootecnia, Belo Horizonte, v. 59, p. 210-217, 2007.
PEREIRA, A. V.; ARIKI, J.; LODDI, M. M.; KISHIBE, R. Bixina como agente pigmentante das gemas de ovos de poedeiras comerciais. In: REUNIÃO ANUAL DA SOCIEDADE BRASILEIRA DE ZOOTECNIA, 38., 2001, Piracicaba, SP. Anais... Piracicaba: SBZ, 2001. p. 839840.

PEREIRA, A. V.; KISHIBE, R.; ARIKI, J.; BORGES, S. A.; LODDI, M. M. Bixina e norbixina como agentes pigmentantes da gema de ovos de poedeiras comerciais. In: REUNIÃO ANUAL DA SOCIEDADE BRASILEIRA DE ZOOTECNIA, 37., 2000, Viçosa, MG. Anais... Viçosa: SBZ, 2000. p. 259.

ROSTAGNO, H. S.; ALBINO, L. F. T.; DONZELE, J. L.; GOMES, P. C.; FERREIRA, A. S.; OLIVEIRA, R. F.; LOPES, D. C. Tabelas brasileiras para aves e suínos: composição de alimentos e exigências nutricionais. Viçosa: UFV, 2000. $141 \mathrm{p}$.

SILVA, D. J.; QUEIROZ, A. C. Análise de alimentos: métodos químicos e biológicos. 3. ed. Viçosa: UFV, 2002. $235 \mathrm{p}$.

SILVA, J. H. V.; ALBINO, L. F. T.; GODOI, M. J. S. Efeito do extrato de urucum na pigmentação da gema dos ovos. Revista Brasileira de Zootecnia, Viçosa, v. 29, p. 14351439, 2000.

TOCCHINI, L.; MERCADANTE, A. Z. Extração e determinação, por CLAE, de bixina e norbixina em coloríficos. Ciência e Tecnologia de Alimentos, Campinas, v. 21, p. 310-313, 2001.

UNIVERSIDADE FEDERAL DE VIÇOSA.SAEG - Sistema de Análises Estatísticas e Genéticas. Versão 8.1. Viçosa, 2003. 301 p.

YABIKU, H. Y.; TAKAHASHI, M. Y. Determinação de bixina em sementes de urucum: estudo colaborativo. Revista do Instituto Adolfo Lutz, São Paulo, v. 52, p. 3136, 1992. 